\title{
Investigation of the geotechnical properties and estimation of the relative density from the standard penetration test in sandy soils (Case study: north east of Iran)
}

Omid Amini ( $\nabla$ khayam130@yahoo.com )

Kerman Graduate University of Technology: Graduate University of Advanced Technology

Arman Khoshghalb

school of civil and environmental enginerig

Mahin Etemadifar

Tarbiat Modares University

\section{Research Article}

Keywords: artificial neural network, multiple regression, standard penetration test, geotechnical properties, vadose zone

Posted Date: August 12th, 2021

DOl: https://doi.org/10.21203/rs.3.rs-781747/v1

License: (c) (1) This work is licensed under a Creative Commons Attribution 4.0 International License.

Read Full License 


\title{
1 Investigation of the geotechnical properties and estimation of the

\author{
Omid Amini ${ }^{1 *}$, Mahin Etemadifar ${ }^{2}$, Arman Khoshghalb ${ }^{3}$ \\ 1- Faculty of Civil and Surveying Engineering, Graduate University of Advanced Technology, \\ Kerman, Iran \\ 2- Department of Geology, Faculty of Science, Tarbiat Modares University, Tehran, Iran \\ 3- School of Civil and Environmental Engineering, UNSW Sydney, Sydney, Australia \\ * Correspondence: khayam130@yahoo.com
}

\begin{abstract}
In the present research, SPT results are adopted to establish relationships for estimation of the relative density in a sandy soil. SPTs are performed in 20 boreholes in Astaneh-ye Ashrafiyeh city in Iran. Laboratory tests including mineralogy, relative density, soil gradation, Atterberg limits, and unit weight were performed on the soil samples. The SPT numbers were then properly corrected. In particular, the correct procedure for correction of the SPT number against the existing overburden effective stress is discussed when the SPT is performed in the vadose zone where the soil may be unsaturated. The soil in the study area is dominantly classified as SP-SM. The relationship between the relative density as one of the most important parameters for dominantly granular soils, with the corrected SPT number $\left(\mathrm{N}_{1(60)}\right)$ and fines content is then
\end{abstract}


26 investigated and discussed using artificial neural network and statistical analysis. Results

27 showed that for the soil of interest, the developed relationship performs better than those

28 established in the literature, hence demonstrating the value of developing locally tuned

29 relationships for important projects.

30 Keywords: artificial neural network, multiple regression, standard penetration test, geotechnical

31 properties, vadose zone

32

33

34

35

36

37

38 1. Introduction

Estimation of geotechnical parameters of soils using simple field tests is a common

40 practice in site investigation studies. Because these tests are simple, inexpensive, and tangible

41 to practicing engineers (Sivrikaya and Tougrol 2006; Sivrikaya et al. 2013; Kayabasi and

42 Gokceoglu 2018). One of these tests is the standard penetration test (SPT) (Bozbey and Togrol

43 2010; Yoshida (1988); Meyerhof 1956; Ching et al. 2017). This test is recently used for

44 predicting mechanical properties of the fine-grained soils (Sivrikaya and Tougrol 2006; Yilmaz

45 2000; Mahmoud 2013). 
46 Many scholars have presented the relationships between the SPT number and geotechnical 47 properties of soils, and many relationships and computational methods have already been 48 developed in this regard (Sivrikaya and Tougrol 2006; Phoon and Kulhawy 1999). In particular, 49 several relations have been suggested for predicting of the relative density of granular soils using 50 the SPT value (Table 1), given the importance of the relative density in characterisation of 51 granular soils. Local relationships established in a particular geologic site may be desirable to 52 universal adjustments (Phoon and Kulhawy 1999; Nia et al. 2017; Abbaszadeh Shahri 2016; 53 Rastegarnia et al. 2017). Furthermore, the effect of soil suction in unsaturated regions of the soil 54 has been overlooked in obtaining many of these correlations, rendering them less reliable in the 55 regions above the water table (Pouranaghiazar et. 2013). The latter issue may lead to correlations 56 over-estimating soil parameters, and hence compromising the safety of geostructures. $* * * * * * * * * * * * * * * * * * * * * * * * * * * * * * * * *$ Table

58 This study aim to develop two models, one based on artificial nural network approach and one based on multiple regression analysis, for estimating of the relative density from the results of the SPT. The relative density is selected as the parameter of interest since it corrleates very well

61 with many engineering properties of granular soils. Test data from 20 boreholes in city of 62 Astaneh-ye Ashrafiyeh, located in northeast of Iran, are used for the developments. Carefull 63 consideration specified to calculate the effective stress correctly above the water table based on 64 soil suction. The parameters that most strongly correlate with the soil relative density are 65 identified from the test data. Derivation and validation of the models are explained and 66 discussed. The application of the models developed along with several well stablished models

67 in the literature for estimation of the relative density using SPT data is then presented and 68 discussed using the data of this study. 


\section{Test site}

71

72

73

74

75

76

77

78

79

80

81 factors are presented in Table 1.

$82 \quad\left(N_{1}\right)_{60}=N_{S P T} \cdot C_{N} \cdot C_{E} \cdot C_{B} \cdot C_{S} \cdot C_{R}$

83 Where, $\left(\mathrm{N}_{1}\right)_{60}$ is the $\mathrm{N}_{60}$ normalized to one atmosphere overburden stress. $\mathrm{C}_{\mathrm{N}}$ is calculated using

84 equation 2( Liao et al.1986)

$85 \quad C_{N}=9.78 \sqrt{\frac{1}{\sigma^{\prime}}}$

86 In which $\sigma^{\prime}$ is the effective overburden stress in $\mathrm{kN} / \mathrm{m}^{2}$. Table 2 shows the score of each 87 correction factor (ASTM 2011).

88 89

The studied region is in Astaneh-ye Ashrafiyeh city in the north east of Iran with geographical coordinates of $37^{\circ} 15^{\prime} 35.38^{\prime \prime} \mathrm{N}$ and $49^{\circ} 56^{\prime} 38.25^{\prime \prime} \mathrm{E}$ (Fig. 1). 20 boreholes were drilled in this area and more than 200 samples were taken from the boreholes. Correct characterisation of the sandy soil of this region is particularly important since liquefaction occured in this area due to Manjil-Rudbar earthquake (magnitude 7.7 Richter) in 1990. Geological formations from Precambrian to Quaternary identified in this area, with some gaps and unconformities in Paleozoic and Mesozoic (Aghanabati 2004).

\section{Standard penetration test (SPT)}

The SPT number is often corrected for different variables. In this study, Equation 1 used to correct the SPT number (Robertson and Fear 1996). The description and values of the correction 
The gradation, Atterberg limits and unit weight of the samples were determined based on

91

92

93

94 the ASTM D421 (ASTM 2007), ASTM D4318 (ASTM 2010) and ASTM D854 (ASTM 2010), respectively. The results of these test are presented in Table 3. Fig. 2 shows a gradation curve of a sample. The soil in the studied area is mainly a uniformly graded sand with angular particles, with a little amount of silt and clay (i.e., SP-SM based on the unified classificacion system).

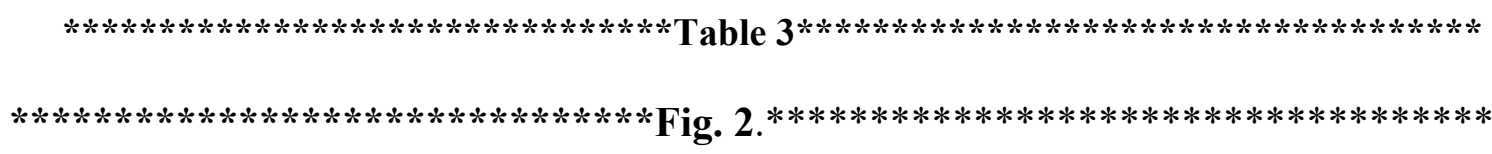

In total, 292 samples from 20 boreholes were extracted and analyised in this study. Statistical characteristics of test data related to fines content, $\mathrm{N}_{1(60)}$, and relative density of the smaples are displayed in Table 4. This table shows that the standard deviatios are considerable, indicating large heterogenety in the soil of the study area. This is often expected in natural soils. Despite this variability in the soil and for the sake of practicality, the whole site is treated as one soil, and all the derivations to follow are based on average soil parameters.

$* * * * * * * * * * * * * * * * * * * * * * * * * * * *$ Table $4 * * * * * * * * * * * * * * * * * * * * * * * * * * * * *$

As an example, the geotechnical properties of the samples taken from borehole 2 are presented in Table 5.

The average corrected SPT number for all the SPT tests was obtained 18. Hence, based on Meyerhof (1956) and Terzaghi and Peck (1967) classifications, the soil of the studied area is categorized as compacted and very dense soil, respectively (see Table 6).

$* * * * * * * * * * * * * * * * * * * * * * * * * * * *$ Table $6 * * * * * * * * * * * * * * * * * * * * * * * * * * * * *$ 
111 Fig. 1 shows the geological map deposits and soil texture map at depths of $10 \mathrm{~m}$ and $20 \mathrm{~m}$. The

112 sediments of the studied site consist predominantly of plagioclase, clinopyroxene, epidote,

113 quartz and carbonate minerals (Fig. 3). The abundance of each one is as follows:

114 Clinopyroxene: The pyroxenes of the samples are dominantly diopside with a little bit of Augite, 115 with a frequency of $10 \%$ and an average size of $0.2 \mathrm{~mm}$.

116 Plagioclase: This mineral is the most abundant mineral in the complex, with a frequency of $40 \%$

117 and a size between 0.1 and $0.3 \mathrm{~mm}$, with a mean magnitude of $0.2 \mathrm{~mm}$.

118 Epidote: This mineral frequency is 5\% and its average size is $0.2 \mathrm{~mm}$.

119 Carbonate particles: Mainly contains calcite and the frequency of these particles is $20 \%$ and 120 varies from 0.1 to $0.3 \mathrm{~mm}$.

121 The other important minerals of these sediments are metallic minerals with an abundance of $12215 \%$ and a range from 0.1 to $0.2 \mathrm{~mm}$. Because the sediments are most commonly composed of 123 minerals isolated from Mafic and Ultramafic rocks, it is likely that these minerals are opaque 124 magnetite. Quartz is also rarely seen in these sediments. The sorting of the particle is good (i.e. 125 the sediments gradation is weak) and rounding is weak (i.e. the sediments particles are angular). 126 The parent rocks of these sediments are mainly carbonate rocks with Mafic composition.

\subsection{The Artificial Neural Netwok (ANN)}

129 ANN is a framework involving a chain of elements that transfer with each other by many 130 inner weights. These weights are continually adjusted throughout the training stage of the 131 network. During ANN analysis, the operator controls the outputs, inputs, layer nodes and hidden 132 layer numbers. Several functions such as Gaussian, Sigmoid, Hyperbolic Tangent and 
133 Hyperbolic Secant are used among the layers. Among these, the Sigmoid function has the main 134 acceptance in engineering uses, mainly due to their simple derivations which facilitate the 135 evaluation of the back propagation errors. The most appropriate ANN for engineering 136 applications is back propagation networks (BPN) (Rumelhart et al. 1986) in which the 137 calculations start with some optional weights, and then the outputs are calculated, and modified 138 by adjusting certain weights using the computed error from the output and estimated values. 139 This procedure is continued until the minimum error is gained. To obtain the optimal network, 140 the try and error process lasts until the lowest error is gotten (Chatterjee et al. 2000). In this 141 study, the optimum ANN to estimate the relative density was obtained when 2 hidden layers

142 were selected, as will be explained later in the paper.

\subsection{Effective stress calculation above the water table}

144 To calculate the effective stress, the effect of suction must be properly considered in vadose 145 zone. The suction values are often small in granular soils, like those dominant in the region of 146 interest in this study, and hence the suction effects can be overlooked in calculation of the 147 effective stresses. However, the procedure to calculate the effective stress is explained here for 148 the sake of completeness, and to be used when the soil of interest contains a considerable amount 149 of fines. To this end, the method of effective stress (Khalili 2004; Ghaffaripour et al. 2019) is 150 used, in which in the unsaturated region of the soil we have,

$151 \sigma^{\prime}=\sigma_{\text {net }}+\chi S$

152 where $\sigma_{\text {net }}$ is the net stress, $\chi$ is the effective stress parameter and $s=u_{a}-u_{w}$ is the soil suction.

153 Where, ua and uw are pore air and water pressures, respectively. In this equation, effecitve stress, 154 pore water and pore air pressures are assumed positive in compression following the soil 155 mechanics convention. 
156 For soils under static load, we can often assume that $u_{a}=0$, so Equation (3) is simplified to 157 equation 4 ,

$158 \sigma^{\prime}=\sigma+\chi s$

159 where $\sigma$ is the total stress. Several models are available in the literature for estimation of the 160 parameter of effective stress. Here, the model presented by Khalili and Khabbaz (1998) is 161 adopted since it is the most accurate method in the litarature. According to this approach and 162 neglecting the hydraulic hysteresis effects, the parameter of effective stress at each point is 163 obtained as follows

$164 \quad \chi=\left\{\begin{array}{cc}1 & s \leq s_{\mathrm{e}} \\ \left(\frac{s_{\mathrm{e}}}{s}\right)^{\Omega} & s>s_{\mathrm{e}}\end{array}\right.$

165 where $\Omega$ is a material parameter with best fit of 0.55 , and $s_{e}$ is the air entry value of the soil.

166 The value of air entry of the soil is obtained from the soil water retention curve (SWRC) (Pasha 167 et al. 2019, 2015). Obtaining the SWRC is however time consuming and the test was not 168 performed on the samples obtained in this study. Therefore, a simple SWRC as presented in 169 Figure 4 was assumed for the samples based on their average gradation curve (Khoshghalb et 170 al. 2015). As seen from this figure, an average air entry value of $3 k P a$ was assumed for the soil, 171 and it has been assumed that the soil reaches a residual degree of saturation of $5 \%$ at a suction 172 of $15 k P a$. $* * * * * * * * * * * * * * * * * * * * * * * * * * * * * * * * * * *$ Figure 4. $* * * * * * * * * * * * * * * * * * * * * * * * * * * *$

174 The suction of the soil can be obtianed using tensiometers in the field, or from the SWRC and 175 the in situ water content or degree of saturation of the soil. Since no tensiometers were used to 
176 obtain the suction of the soil, the soil suction was estimated using the degree of saturation of the

177 soil samples, and the assumed SWRC presented in Figure 4. For the samples saturated above

178 the water table (due to capillary rise), the suction of the sample were obtained from:

$179 s=-\gamma_{w} h$

180 where $\gamma_{\mathrm{w}}$ is the unit weight of water, and $h$ is the height of the point of interest above the water

181 table. For the samples with the degree of saturation less than $5 \%, s=0$ was assumed in the 182 calculations.

\section{Relative density estimation relationships}

The dependency of the relative density of the samples to fines content (FC), N1(60), plastic 185 limit (PL) and depth were investigated as shown in Figure 5. According to these results, the 186 fines content and $\mathrm{N}_{1(60)}$ were found to have the greatest effects on the relative density of the soil 187 samples in the studied area. A number of previous studies have also shown the importance of 188 fines content and effective overburden pressure on the behaviour of sandy soils (Payan et al. 189 2017; Mujtaba et al. 2017; Meyerhof 1956). The ability of the SPT number to estimate the 190 relative density of the coarse-grained soils has also been confirmed by other researchers 191 (Mahmoud 2013; Phoon and Kulhawy 1999; Hettiarachchi and Brown 2009). On this basis, 192 fines content and $\mathrm{N}_{1(60)}$ were selected as the main independent variable to estimate the relative 193 density of the soil of interest using artificial neural network and multiple regression analysis. 
As shown in Fig. 6, using neural network toolbox of MATLAB, version 2014, the designed network contains 2 hidden layers with two inputs and one output. Inputs contain $\mathrm{N}_{1(60)}$ and fines content, and the output is the parameter of interest, i.e., the relative density (Dr).

$* * * * * * * * * * * * * * * * * * * * * * * * * * * * * * * * * * *$ Figure 6

The conveying function of the neuron was chosen as Purelin for the output layer and Sigmoid in the middle layer. Different networks with various neurons in the hidden layer were trained and the optimum neurons were chosen according to the error levels in the try and error process of training the network. Algorithms of Bayesian-regularization and Levenberg Marquardt were used for overfitting decreasing and training actions, respectively (Beeravelli et al. 2018; Gorgani et al. 2019). Overfitting occurs when an algorithm accurately predicts the data used in the training of the algorithm, but performs poorly for the data sets outside of the training set. In the Bayesian-regularization algorithm, the training is stopped when the error corresponding to the training and testing data sets is the least possible (García-Díaz et al. 1992; Ahmadi and Shybt 2020; Salazar et al. 2020; Golmohammadi et al. 2014). To develop a reliable network, the 292 data of the study were randomly divided into three sets: training, validation and testing sets. The ratios considered in the separation are $70 \%$ of train (204 data), 15\% of validation (44 data), and 15\% of test (44 data). The training set was used to train the algorithm. The validation set was used to ensure that the network is not highly dependent on the training data sets, hence preventing overfitting. The testing set was not used during the training, and was reserved to test the network robustness in predicting new data (Ansari and Hashemi 2017).

Figure 8 depicts the error of the network associated with training, validation and testing data sets for different epoch numbers. As the number of epochs increases, the error of all data sets decreases, until a point is reached where the error of the validation data set starts increasing. 
219 This indicates that overfitting is likely to occur after this point, as also indicated by a slight 220 increase in the error of the test data set after epoch number 6. Hence, the optimum number of 221 epochs was deemed 6 for the network of this study, and the training process was stopped at this 222 epoch number (Fig. 7).

224 To avoid adverse effects of very large or extremely small values of input variables on the 225 network weights, all input data are first normalized using Equation 7, so that they fall between $226-1$ and 1 ,

$$
X_{i}=2\left(\frac{X-X_{\min }}{X_{\text {max }}-X_{\min }}\right)-1
$$

The precision of the estimated relative density based on the optimum neural network tested by computing the $\mathrm{R}^{2}$ and root mean square error (RMSE) index which is calculated as follows,

231 in which $\mathrm{y}$ is the measured Dr, $y^{\prime}$ is the estimated Dr by the model, $\mathrm{n}$ is the total number of data 232 and $s^{2}$ is the sample variance.

The ststistical parameters when various hidden layers are used in the network are presented in Table 7. From this result, the model with 2 hiddern layers was selected as the optimum model 235 since no meaningful improvement is observed in the predictions for higher number of hidden layers. The correlation between the measured data and the results of this optimum model for the 237 training, validation, testing, and entire data sets are ilusterated in Fig. 8. 
240 For comparison, Figure 9 presents the estimated (using the neural network method) versus 241 measured (experimental results) values of the relative densities for all the test data. The 242 coefficient of determination for the estimated values using the neural network approach is $243 \quad \mathrm{R}^{2}=0.90$ (Fig. 10).

\subsection{Relative density estimation using multiple linear regression(MLR)}

Using the statistical package for the social sciences (SPSS), version 21, the MLR analysis

247 was also used to develop a relationship between the relative density, $\mathrm{N}_{1(60)}$ and fines content.

248 The most common way for constructing a MLR model is the step by step (Namdar and Sarabiyan 249 2020; Radhy 2019) method which has been adopted in this study. In this approach, the first 250 independent variable, which has the maximum effect on dependent variable, is selected and the 251 regression model is developed accordingly. The other potential independent variables are then 252 added to the regression model one by one to examine if they can meaningfully influence the 253 regression model or not (decided by performing a T-test). The regression model gradually 254 improved by inclusion of more relevant indepdent variables.

255 Such a regression analysis was performed on the data of this study, resulting in the following 256 relationshp:

$257 \quad D r=1.45 N_{1(60)}-0.17 F C+45.60$

258 where, FC is the fines content (\%), and Dr is the relative density in \%. Beta coefficients, which 259 express the relative effect of each independent variable on the predictions in terms of 260 standardized data, were obtained for both independent variabales of this study as presented in

261 Table 8. The results indicated that $\mathrm{N}_{1(60)}$ has a higher effect on the relative density than fines 262 content. 
264 The $F$-ratio in the one way analysis of variance (ANOVA) test shows that the $\mathrm{N1}_{(60)}$ and $\mathrm{FC}$ 265 statistically significantly predict the the $\mathrm{D}_{\mathrm{r}}$ variable, $F(2,289)=1063, p<.005$ (i.e., the MLR 266 model is an accurate fit of the variables). I.e., the model with $0.95 \%$ confidence is significant 267 and based on available data this model is able to express relative density changes.

268 The significant level (Sig.) in the T-test (the Test of the presecnce of independent variables in 269 the model) in Table 8 indicates the effect of the coefficient of each independent variables and 270 the constant on the equiton. A value less than $0.05($ Sig.<0.05) indicates that the coefficient is 271 statistically significantly different to zero and the corresponding variable has a meaningful effect 272 on the regression model and must be entered into the model. As can be seen from Table 8 , the 273 Sig. values of both independent valiables are less than 0.05 , hence, both the selected independent 274 variables are suitable for estimating the relative density. This is in agreement with the analysis 275 presented in Fig. 5, as discussed earlier in the paper.

276 The errors or residuals are the difference between the real and the predicted values using the 277 equation of regression. There is no chance for using the regression equation, if the error is 278 correlated with each other. If the Durbin-Watson (DW) statistic is in a range of 1.50-2.5, the 279 residuals are not correlated (Montgomery et al. 2012). The DW statistic for multiple regression 280 developed in this study was obtained 1.82 as presented in Table 8 , hence, the assumption of 281 independence of errors was fulfilled in this analysis.

282 The collinearity suggests that two predictors are a complete linear combination of each other. 283 As the value of collinearity increases, the error in estimating the coefficients of the equation 284 increases. To check the multicollinearity of independent variables, the concept of "tolerance" of 285 independent varialbles are used. The tolerance of each independent variable is obtained as 286 follows, 
287 Tolerance $=1-\left(R_{J}\right)^{2}$

288 where, $\mathrm{Rj}^{2}$ is the coefficient of determination of the regression model with the $j$ th descriptive 289 variable as the dependent variable and other descriptive variables as independent variables.

290 The tolerance of each independent variable is a measure of its influence on the predications that 291 is not captured by other independent variables, therefore very small tolerance values for a 292 predictor show that the predictor is superfluous, and perhaps a function of other independent 293 variables. Often when the tolerance of an independent variable is less than 0.10 , further checks 294 are needed to investigate if that independent variable can be removed or not. Low tolerances 295 indicate that the influencing parameters are not propertly captured, hence the model may not be 296 reliable (Namdar and Sarabiyan 2020; Radhy 2019). It is worth mentioning that the invese of 297 the Tolerance, which is called the variance inflation factor (VIF), is also used in the literature to 298 check the multicollinearity of independent varialbls. In the regression model developed in this 299 study the tolerance values for inputs are higher than 0.10 and the VIF values are lower than 10 , 300 and therefore, multicollinearity does not cause any problems in this MLR (Table 8).

301 Fig. 10 shows that the supposition of normality of residuals is fulfilled in the regression 302 developed in this study.

304 Figure 11 shows the developed relationship along with all the data of this study.

307 5.3. Comparission with previous relatinships

In this section, several well stablished relationships in the literature for prediction of soil relative density based on the SPT number is adopted to see how well they can predict the relative 
310 density of the soil of interest compared to the relationships developed in this study. The RMSE

311 and $\mathrm{R}^{2}$ are used to evaluate the performance of each model. The models adopted for evaluation

312 are as follows:

313 Mujtaba et al. model: Mujtaba et al. (2017) presented the following model to estimate the 314 relative density in SP-SM soils based on, N60, atmospheric pressure $(\mathrm{kPa})$, and effective stress $315(\mathrm{kPa})$.

$316 D_{r}(\%)=1.96 N_{60}-19.2\left(\frac{P_{a}}{\sigma_{v}^{\prime}}\right)^{0.23}+29.2$

317

Gibbs and Holtz model: Gibbs and Holtz (1957) presented the following relationship to estimate 319 the relative density (\%) using the effective overburden stress (psi) and SPT-N for sandy soils,

$320 \quad D_{r}=\sqrt{\frac{S P T-N}{1.7\left(10+\sigma_{v}^{\prime}\right)}}$

321 Meyerhof model: Meyerhof (1956) proposed a relationship similar to the Gibbs and Holtz [41]

322 relationship between the relative density (\%), SPT-N and effective overburden stress (psi) for 323 sandy soils in the form of Eq. (13).

$324 D_{r}=\sqrt{\frac{S P T-N}{\left(17+24 \frac{\sigma_{v^{\prime}}}{98}\right)}}$

325 Yoshida model: Yoshida (1988) suggested a relationship between the relative density (\%), $\mathrm{N}_{60}$ 326 and effective overburden stress $(\mathrm{kPa})$ for sandy soils in the form of Eq. (14).

$327 D_{r}=25 N_{60}{ }^{0.46} \sigma_{v}{ }^{\prime-0.12}$

328 Kibria and Masood model: Kibria and Masood (1998) presented Equation (15) to estimate the 329 relative density in $\mathrm{SM}$ soils based on, $\mathrm{N}_{1(60)}$.

330

$D_{r}=16.5 \sqrt{N_{1(60)}}$ 
331 All these models were adopted to estimate the relative densities for the data of this study. The 332 results are shown in Figure 12 for Mujtaba et al. model and Gibbs and Holtz (1953) model, in 333 Figure 13 for Meyerhof model and Yoshida and Ikemi model and in Figure 14 for Kibria and 334 Masood model and the model presented in this study. The results show that except for the Kibria 335 and Masood model, the rest of the corrlations perform poorly for the soil of this study. The 336 Kibria and Masood model is a crude model which does not include the very important effect of 337 the existing effective stress in estimation of the relative density. Hence, the good performance 338 of this model for the data of this study is, at least in parts, coincidence. Figures 12 to 14 shows 339 that the correlation proposed in this study outperforms all other tested models for the data of this 340 study.

344 Finally, comparing the ANN results with the MLR results, the ANN manifests a higher value of 345 the coefficient of determination and a lower value of the $\mathrm{RSME}\left(\mathrm{R}^{2}=0.90\right.$ and $\mathrm{RSME}=4.03$ seen 346 in Fig. 9) compared to those of the MLR analysis $\left(\mathrm{R}^{2}=0.88\right.$ and $\mathrm{RSME}=4.50$ seen in Fig. 14), 347 indicating the superiority of the neural network approach.

\section{Conclusions}

Multiple regression analysis and neural network approach were adopted to develop 350 relationships for estimation of the relative density using SPT in a sandy soil. The procedures of 351 identifying the independent variables, constructing the relationships and checking their validity 
352 were explained in details. In particular, the treatment of the effect of suction when the SPT test

353 is performed in the vadose zone was explained, an aspect which is often overlooked in the

354 literature. The relationships obtained were tested against several well stablished models in the

355 literature for estimation of the relative density from SPT results for the data of this study. The

356 comparisons showed that the locally developed models outperformed the established models in

357 the literature. In particular, some established relationships in the literature performed very

358 poorly in estimation of the relative densities for the soil of interest. Between the two approachs

359 adopted, the neural network yeilded better results than the multivariate regression for prediction

360 of the soil relative density. The results indictes that when high accuracies are needed,

361 relationships that are particularly developed for a region of interest must be developed as they

362 can be much more accurate than the stablished relationships.

\section{Acknowledgements}

364 The authors wish to thank Mr. Sina Hajati Ziabari for data preparation that used in this

365 paper.

\section{Refrences}

Abbaszadeh Shahri A (2016) Assessment and prediction of liquefaction potential using 368 different artificial neural network nodels: a case study. Geotech Geol Eng 34:807-815

369 Aghanabati A (2004) Geology of Iran. Geological survey of Iran

Ahmadi R. and Shybt SAH. (2020) Study of artificial neural networks in information

371 security risk assessment, JMAS 8(2). https://doi.org/10.24200/jmas.vol8iss02pp1-10.

372 Ansari Y. and Hashemi A. (2017) Neural Network Approach in Assessment of Fiber

373 Concrete Impact trength, J. Civ. Eng. Mater. Appl., 1(3), 88-97. doi:

374 10.15412/J.JCEMA.12010301.

375 ASTM (2010) Standard test methods for liquid limit, plastic limit, and plasticity index of 376 soils. In: The American Society for Testing and Materials, West Conshohocken, United States. 377 D4318. 
ASTM (2010) Standard Test Methods for Specific Gravity of Soil Solids by Water Pycnometer. Astm D854 1-7. https://doi.org/10.1520/D0854-10.2

ASTM (2011) ASTM D1586-11: Standard Test Method for Standard Penetration Test ( SPT ) and Split-Barrel Sampling. ASTM International, West Conshohocken, PA, 1-9

ASTM D (2008) 1586 (2008) Standard test method for standard penetration test (SPT) and split barrel sampling of soils. Annual book of ASTM standards

ASTM D421 (2007) Standard Test Method for Particle-Size Analysis of Soils. In: Astm. pp 1-8

Beeravelli VN. Chanamala R, Kancherla PR. (2018) an Artificial Neural Network and Taguchi Integrated Approach to the Optimization of Performance and Emissions of Direct Injection Diesel Engine, EJOSDR 2(2), 1-16. https://doi.org/10.20897/ejosdr/85412.

Bozbey I, Togrol E (2010) Correlation of standard penetration test and pressuremeter data: A case study from Istanbul, Turkey. Bull. Eng. Geol. Environ 69:505-515 https://doi.org/10.1007/s10064-009-0248-4

Chatterjee A, Ayadi OF, Boone BE (2000) Artificial neural network and the financial markets: A survey. Managerial Finance 26:32-45

Ching J, Lin G-H, Phoon K-K, Chen J (2017) Correlations among some parameters of coarse-grained soils - the multivariate probability distribution model. Can. Geotech. J. 54:1203-1220. https://doi.org/10.1139/cgj-2016-0571

Coduto DP (2015) Foundation design: principles and practices. Pearson

Cubrinovski M, Ishihara K (1999) Empirical correlation between SPT N-value and relative density for sandy soils. Soils Found. 39:61-71

Cubrinovski M, Ishihara K (2001) Correlation between penetration resistance and relative density of sandy soils

García-Díaz N, Verduzo-Ramirez A, Garcia-Virgen J, Muñoz L. (2016), “Applying Absolute Residuals as Evaluation Criterion for Estimating the Development Time of Software Projects by Means of a Neuro-Fuzzy Approach”, J. Inform. Systems. Eng., 1(4), 46-57. http://ridda2.utp.ac.pa/handle/123456789/2915.

Ghaffaripour O, Esgandani GA, Khoshghalb A, Shahbodaghkhan B (2019) Fully coupled elastoplastic hydro-mechanical analysis of unsaturated porous media using a meshfree method. Int J Numer Anal Methods Geomech DOI: 101002/nag2931

Gibbs HJ, Holtz WG (1957) Research on determining density of sands by Spoon Penetration Standart. In: 4th Int. Conf. Soil Mech. Found. Eng., London, 1. pp 35-39

Golmohammadi, A.M., Tavakkoli-Moghaddam, R., Jolai, F. and Golmohammadi, A.H. (2014), "Concurrent cell formation and layout design using a genetic algorithm under dynamic conditions”, UCT. J. Resea. Scien. Engineer.Techno., 2(1), 8-15.

Gorgani, H.H., Maghsoudi, P. and Sadeghi, S. (2019), “An Innovative Approach for Study of Thermal Behavior of an Unsteady Nanofluid Squeezing Flow between Two Parallel Plates Utilizing Artificial Neural Network", EJOSDR 3(1): p.em0069. https://doi.org/10.20897/ejosdr/3935. 
Hettiarachchi H, Brown T (2009) Use of SPT Blow Counts to Estimate Shear Strength Properties of Soils: Energy Balance Approach. J. Geotech. Geoenviron. 135:830-834. https://doi.org/10.1061/(ASCE)GT.1943-5606.0000016

Kayabasi A, Gokceoglu C (2018) Liquefaction potential assessment of a region using different techniques (Tepebasi, Eskisehir, Turkey). Eng. Geo. 246:139-161

Khalili N, Geiser F, Blight GE (2004) Effective stress in unsaturated soils: Review with new evidence. Int. J. Geomech 4:115-126

Khalili N, Khabbaz MH (1998) A unique relationship for shear strength determination of unsaturated soils. Geotechnique 48:681-688

Khoshghalb A, Pasha AY, Khalili N (2015) A fractal model for volume change dependency of the water retention curve. Geotechnique 65:141-146

Kulhawy FH, Mayne PW (1990) Manual on estimating soil properties for foundation design

Liao BSSC, Asce AM, Whitman R V, Asce F (1986) OVERBURDEN CORRECTION FACTORS FOR SPT IN SAND By Samson S. C. Liao, 1 A. M. ASCE and Robert V. Whitman, 2 F. ASCE. 112:373-377

Mahmoud MAAN (2013) Reliability of using standard penetration test (SPT) in predicting properties of silty clay with sand soil. Int. j. civ. 3:545-556. https://doi.org/10.6088/ijcser.201203013050

Meyerhof GG (1956) Penetration tests and bearing capacity of cohesionless soils. J. Soil Mech. Found. Div. 82:1-19

Montgomery DC, Peck EA, Vining GG (2012) Introduction to linear regression analysis. John Wiley \& Sons

Mujtaba H, Farooq K, Sivakugan N, Das BM (2017) Evaluation of relative density and friction angle based on SPT-N values. J. Korean Soc. Civ. 22:572-585

Namdar, A. and Sarabiyan, S. (2020), "Relationship between emotional control and marital satisfaction in 20 to 45 years old boy in Torbat Heydarieh", JSSHR, 8(3), 18-25. DOI: https://doi.org/10.24200/jsshr.vol8iss3pp\%25p.

Nia, A.R., Lashkaripour, G.R. and Ghafoori, M. (2017), "Prediction of grout take using rock mass properties. Bull. Eng. Geol. Environ”, 76(4), 1643-1654. https://doi.org/10.1007/s10064-016-0956-5.

Pasha AY, Khoshghalb A, Khalili N (2015) Pitfalls in interpretation of gravimetric water content--based soil-water characteristic curve for deformable porous media. Int. J. Geomech 16:D4015004

Pasha AY, Khoshghalb A, Khalili N (2019) Can degree of saturation decrease during constant suction compression of an unsaturated soil? Comput Geotech 106:199-204

Payan M, Senetakis K, Khoshghalb A, Khalili N (2017) Characterization of the smallstrain dynamic behaviour of silty sands; contribution of silica non-plastic fines content. Soil Dyn Earthq Eng 102:232-240 
Phoon K-K, Kulhawy FH (1999) Evaluation of geotechnical property variability. Can. Geotech. J. 36:625-639

Pouranaghiazar M, Russell AR, Khalili N (2013) The cone penetration test in unsaturated sands. Géotechnique 63:1209-1220. https://doi.org/10.1680/geot.12.p.083

Radhy ZH. (2019), “Application of Multiply Regression Linear Model and New Technology Method in Estimating Learning and Education of Students", IEJME., 14(1), 8790 .

Rastegarnia, A., Sohrabibidar, A., Bagheri, V., Razifard, M. and Zolfaghari, A., 2017. Assessment of relationship between grouted values and calculated values in the Bazoft Dam Site. Geotech Geol Eng, 35(4), pp.1299-1310.

Robertson PK, Fear CE (1996) Soil liquefaction and its evaluation based on SPT and CPT. In: Proc. NCEER Workshop on Evaluation of Liquefaction Resistance

Rumelhart DE, Hinton GE, Williams RJ (1986) Learning representations by backpropagating errors. nature 323:533

Salazar, L.H., Fernandes, A., Dazzi, R., Garcia, N. and Leithardt, V.R.Q. (2020), "Using Different Models of Machine Learning to Predict Attendance at Medical Appointments". J Inform Systems Eng, 5(4). https://doi.org/10.29333/jisem/8430.

Sivrikaya O (2009) Comparison of Artificial Neural Networks models with correlative works on undrained shear strength. Eurasian Soil Science 42:1487-1496. https://doi.org/10.1016/S0920-5489(02)00077-6

Sivrikaya O, Kayadelen C, Cecen E (2013) Prediction of the compaction parameters for coarse-grained soils with fines content by MLR and GEP. Acta Geotech. Slov. 10:29-41

Sivrikaya O, Tougrol E (2006) Determination of undrained strength of fine-grained soils by means of SPT and its application in Turkey. Eng. Geo. 86:52-69

Terzaghi K, Peck RB (1967) Soil mechanics in engineering pratice

Yilmaz I (2000) Evaluation of shear strength of clayey soils by using their liquidity index. Bull. Eng. Geol. Environ. 59:227-229. https://doi.org/10.1007/s100640000056

Yoshida Y (1988) Empirical formulas of SPT blow-counts for gravelly soils. Penetration Testing 1988, ISOPT-1 1:381-387

\section{List of tables and figures}

Table 1. Relationships for estimation the Dr based on the SPT

Table 2. Corrections to the SPT N value [20] 
Table 3. Mean values of the main characteristics of the soil of interest

491 Table 4. Statistical characteristics of the fines content, $\mathrm{N}_{1(60)}$ and relative density obtained from the 20

492 boreholes used in this study

493 Table 5. Geotechnical properties of the samples taken from borehole $2(B H 2)$

494 Table 6. Classification of the soil in the studied area based on Meyerhof (1956) and Terzaghi and Peck

495 (1967) classifications

496 Table 7. Performance of the ANN models using various hidden layers

497 Table 8. The VIF, Tolerance, Beta coeffcients, and T-test results for the MLR model

498 Table 9. Results of the ANOVA test to check the suitability of the regression model

Figure 1. Geological characteristics of the study area (a) Geological map deposits; (b) soil texture map

502 at depth $10 \mathrm{~m}$; and (c) soil texture map at depth $20 \mathrm{~m}$

503 Figure 2. Sketch of the standard penetration test instrumentation [42]

504 Figure 3. Average grain size distribution of the studied soil

505 Figure 4. Samples of sediments of the studied soil

506 Figure 5. The assumed SWRC for the samples based on their gradation curves.

507 Figure 6. The dependency of the relative density to other parameters for the studied soil

508 Figure 7. Schematic view of the algorithm used in the ANN model.

509 Figure 8. Variation of the MSE with the number of epochs in the ANN model

510 Figure 9. Relative density predictions for various data sets using the ANN model

511 Figure 10. The performance of the ANN model compared to that of the MLR

512 Figure 11. Histogram of the residual values using the regression model

513 Figure 12. Dependency of Dr to N1 and FC; experimental data and the regression model.

514 Figure 13. Evaluation of the Mujtaba et al. model, and Gibbs and Holtz (1957) model

515 Figure 14. Evaluation of the Meyerhof model, and Yoshida and Ikemi model 


\section{TABLE}

\section{Table 1}

\begin{tabular}{|c|c|c|c|}
\hline Equation & Remarks & Refrences & Soil type \\
\hline$D_{r}(\%)=1.96 N_{60}-19.2\left(\frac{P_{a}}{\sigma_{v}^{\prime}}\right)^{0.23}+29.2$ & $\begin{array}{c}\sigma_{v}{ }^{\prime} \text { is effective overburden } \\
\text { stress in } \mathrm{kPa}, \mathrm{p}_{\mathrm{a}} \text { is } \\
\text { atmospheric pressure in } \\
\mathrm{kPa}, \mathrm{N}_{60} \text { is corected } \mathrm{N} \\
\text { values for } 60 \text { percent of } \\
\text { energy }\end{array}$ & [34] & sandy soils \\
\hline$D_{r}(\%)=\sqrt{\frac{S P T-N}{1.7\left(10+\sigma_{v}{ }^{\prime}\right)}}$ & $\begin{array}{c}\sigma_{v}{ }^{\prime} \text { is effective overburden } \\
\text { stress in psi, SPT-N is raw } \\
\text { SPT number }\end{array}$ & [41] & clean sands \\
\hline$D_{r}=\sqrt{\frac{S P T-N}{\left(17+24 \frac{\sigma_{v}{ }^{\prime}}{98}\right)}}$ & $\begin{array}{c}\sigma_{v}{ }_{v} \text { is effective overburden } \\
\text { stress in } \mathrm{kPa}, \mathrm{Dr} \text { is in } \\
\text { fraction, SPT-N is raw } \\
\text { SPT number }\end{array}$ & [6] & $\begin{array}{l}\text { for clean } \\
\text { sands }\end{array}$ \\
\hline$D_{r}=\sqrt{\frac{N_{1(60)}}{C_{P} C_{A} C_{O C R}}}$ & $\begin{array}{l}\mathrm{N}_{1(60)}, \text { is normalized } \mathrm{N}_{60} \\
\text { to overburden stress, Dr is } \\
\text { in fraction, } \\
\mathrm{C}_{\mathrm{P}}, \mathrm{C}_{\mathrm{A}} \text { and } \mathrm{C}_{\mathrm{OCR}} \text { are } \\
\text { correction factors for grain } \\
\text { size, aging and over- } \\
\text { consolidation }\end{array}$ & {$[35]$} & - \\
\hline$D_{r}(\%)=25 N_{F}^{0.46} \sigma_{v}{ }^{\prime-0.12}$ & $\begin{array}{c}\sigma_{v}{ }^{\prime} \text { is effective overburden } \\
\text { stress in kPa, } \mathrm{N}_{\mathrm{F}} \text { is field } \\
\text { SPT-N }\end{array}$ & [5] & for sand \\
\hline$\left.D_{r}(\%)=\sqrt{\left[\frac{N_{F}\left(0.23+\frac{D_{50}}{2}\right)}{9}\right.}\left(\frac{98}{\sigma_{v}{ }^{\prime}}\right)\right]$ & $\begin{array}{c}\mathrm{N}_{\mathrm{F}} \text { is field SPT-N, } \mathrm{D}_{50} \text { is } \\
\text { median grain size in } \\
\text { millimeter }, \sigma_{v}{ }^{\prime} \text { is } \\
\text { effective overburden stress } \\
\text { in } \mathrm{kPa} \\
\end{array}$ & [43] & granular soil \\
\hline$D_{r}(\%)=16.5 \sqrt{N_{1(60)}}$ & $\begin{array}{l}\mathrm{N}_{1(60)} \text {, is normalized } \mathrm{N}_{60} \\
\text { to overburden stress, } \mathrm{Dr} \text { is } \\
\text { in percentage }\end{array}$ & $\begin{array}{l}\text { Kibria and Masood } \\
\text { (1998) }\end{array}$ & silty sands \\
\hline$D_{r}=\sqrt{\frac{N\left(e_{\max }-e_{\min }\right)^{1.7}}{9}\left(\frac{98}{\sigma_{v}{ }^{\prime}}\right)^{1 / 2}}$ & $\begin{array}{c}\text { Dr is in fraction, } \sigma_{v}{ }^{\prime} \text { is } \\
\text { effective overburden stress } \\
\text { in } \mathrm{kPa}, \mathrm{N} \text { is raw SPT } \\
\text { number }\end{array}$ & [44] & sandy soils \\
\hline
\end{tabular}


Table 2

\begin{tabular}{|c|c|c|}
\hline Correction Factor & Equipment Variable & Typical value \\
\hline \multirow{3}{*}{$\mathrm{C}_{\mathrm{E}}:$ the energy ratio for hammer type } & Donut Hammer & 0.5 to 1.0 \\
\hline & Safety Hammer & 0.7 to 1.2 \\
\hline & Automatic Hammer & 0.8 to 1.5 \\
\hline \multirow{3}{*}{$\mathrm{C}_{\mathrm{B}}:$ the correction factor of theborehole diameter } & $65-155 \mathrm{~mm}$ & 1 \\
\hline & $150 \mathrm{~mm}$ & 1.05 \\
\hline & $200 \mathrm{~mm}$ & 1.15 \\
\hline \multirow{2}{*}{$\mathrm{C}_{\mathrm{S}}:$ the correction factor of the sampler } & Standard Sampler & 1 \\
\hline & Non-Standard Sampler & 1.1 to 1.3 \\
\hline \multirow{4}{*}{$\mathrm{C}_{\mathrm{R}}=$ the correction factor of the drilling rod length } & $3-4 m$ & 0.75 \\
\hline & $4-6 m$ & 0.85 \\
\hline & $6-10 m$ & 0.95 \\
\hline & $>10 \mathrm{~m}$ & 1 \\
\hline
\end{tabular}

537 
548

549

550

551

552

553

554

555

556

557

558

559

560

561

562

Table 3

\begin{tabular}{cccccccccc}
\hline $\mathrm{e}_{\min }$ & $\mathrm{e}_{\max }$ & $\mathrm{Cu}$ & $\mathrm{Cc}$ & $\begin{array}{c}\mathrm{PL} \\
(\%)\end{array}$ & $\begin{array}{c}\mathrm{PI} \\
(\%)\end{array}$ & $\begin{array}{c}\text { Specific } \\
\text { Gravity }\end{array}$ & $\begin{array}{c}\text { Unit weight } \\
\left(\mathrm{kN} / \mathrm{m}^{3}\right)\end{array}$ & $\begin{array}{c}\text { Minimum dry unit } \\
\text { weight }\left(\mathrm{kN} / \mathrm{m}^{3}\right)\end{array}$ & $\begin{array}{c}\text { Maximum dry } \\
\text { unit weight }\left(\mathrm{kN} / \mathrm{m}^{3}\right)\end{array}$ \\
\hline 0.45 & 0.80 & 2.2 & 1.3 & 71 & 6 & 2.67 & 17.1 & 13.6 & 17.7 \\
\hline
\end{tabular}

563

564

565

566

567

568

569

570

571

572 
575

576

577

578

579

580

581

582

583

584

585

586

Table 4

587

588

\begin{tabular}{ccccc}
\hline Parameters & Min. & Max. & Mean & Std. Deviation \\
\hline $\mathrm{FC}$ & 6 & 72 & 23.36 & 18.32 \\
$\mathrm{~N}_{1(60)}$ & 6 & 48 & 18.15 & 6.28 \\
$\mathrm{Dr}$ & 45 & 100 & 67.84 & 13.00 \\
\hline
\end{tabular}

589

590

591

592

593

594

595

596

597 


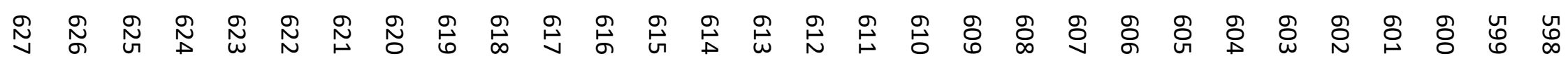

产

\begin{tabular}{|c|c|c|c|c|c|c|c|c|c|c|c|c|}
\hline $\begin{array}{c}\text { Ground } \\
\text { water } \\
\text { level }\end{array}$ & $\begin{array}{c}\text { Depth } \\
\text { (m) }\end{array}$ & $\begin{array}{c}\text { Overburden } \\
\text { Stress } \\
\text { (kPa) } \\
\text { Total }\end{array}$ & $\begin{array}{c}\text { Effective } \\
\text { Overburden } \\
\text { Stress } \\
(\mathrm{kPa})\end{array}$ & $\begin{array}{c}\text { Fines } \\
\text { Content } \\
(\%)\end{array}$ & $\begin{array}{l}\text { Soil } \\
\text { type }\end{array}$ & $\begin{array}{c}\text { Unit } \\
\text { weight } \\
\left(\mathrm{kN} / \mathrm{m}^{3}\right)\end{array}$ & $N$ & $C_{E} * C_{B} * C_{S} * C_{R}$ & $C N$ & $N_{1(60)}$ & $\begin{array}{c}\text { Relative } \\
\text { Density } \\
\quad(\%)\end{array}$ & $\begin{array}{c}D_{50} \\
(\mathrm{~mm})\end{array}$ \\
\hline \multirow{8}{*}{$4.1 m$} & 3.5 & 57.8 & 61.82 & 24 & Sand & 16.5 & 14 & 0.79 & 1.24 & 14 & 69.5 & 2.0 \\
\hline & 5 & 82.5 & 73.67 & 24 & Sand & 16.5 & 13 & 0.9 & 1.15 & 14 & 65.0 & 2.0 \\
\hline & 9.5 & 159.6 & 106.65 & 12 & Sand & 18.7 & 11 & 0.97 & 0.96 & 10 & 56.8 & 0.2 \\
\hline & 11 & 187.7 & 119.99 & 12 & Sand & 18.7 & 10 & 0.98 & 0.9 & 9 & 53.2 & 0.2 \\
\hline & 13 & 226.1 & 138.82 & 27 & Sand & 19.5 & 17 & 0.99 & 0.84 & 14 & 62.5 & 2.0 \\
\hline & 14.5 & 255.3 & 153.36 & 27 & Sand & 19.5 & 11 & 0.99 & 0.80 & 9 & 51.7 & 2.0 \\
\hline & 16 & 284.6 & 167.9 & 27 & Sand & 19.5 & 14 & 1.00 & 0.76 & 11 & 55.1 & 2.0 \\
\hline & 17.5 & 311.4 & 180.04 & 34 & Sand & 16.5 & 14 & 1.00 & 0.74 & 10 & 54.0 & 0.1 \\
\hline
\end{tabular}


631

632

633

634

635

636

Table 6

\begin{tabular}{|c|c|c|c|c|c|}
\hline \multicolumn{2}{|c|}{$[6]$} & & \multicolumn{2}{|c|}{$[24]$} & \\
\hline SPT N & Soil packing & Present study & SPT N & Soil packing & Present study \\
\hline$<4$ & Very loose & $<2$ & Very loose & \\
\hline $4-10$ & Loose & & $2-4$ & Loose & \\
\hline $10-30$ & Compact & N=18 & $4-8$ & medum & \\
\hline $30-50$ & Dense & & $8-15$ & Dense & \\
\hline$>50$ & Very Dense & & $15-30$ & Very Dense & \\
\hline & & & $>50$ & Extremely & \\
\hline
\end{tabular}

637

638

639

640

641

642

643

644

645

646

647

648 
651

652

Table 7

\begin{tabular}{cccccccc}
\hline Hidden Layer & 1 & 2 & 3 & 5 & 7 & 9 & 10 \\
\hline $\begin{array}{c}\text { R Square } \\
\text { Training }\end{array}$ & 0.88 & 0.90 & 0.90 & 0.90 & 0.90 & 0.88 & 0.92 \\
$\begin{array}{c}\text { R Square } \\
\text { Validation }\end{array}$ & 0.87 & 0.90 & 0.94 & 0.96 & 0.94 & 0.94 & 0.90 \\
$\begin{array}{c}\text { R Squrae } \\
\quad \text { Test }\end{array}$ & 0.90 & 0.92 & 0.92 & 0.92 & 0.90 & 0.92 & 0.88 \\
$\begin{array}{c}\text { R Squrae } \\
\text { Total }\end{array}$ & 0.88 & 0.90 & 0.90 & 0.90 & 0.90 & 0.90 & 0.90 \\
$\quad \begin{array}{c}\text { RMSE } \\
\text { Training } \\
\text { RMSE }\end{array}$ & 0.17 & 0.15 & 0.15 & 0.15 & 0.15 & 0.15 & 0.13 \\
$\begin{array}{c}\text { Validation } \\
\text { RMSE } \\
\text { Test }\end{array}$ & 0.14 & 0.16 & 0.11 & 0.11 & 0.11 & 0.13 & 0.14 \\
\hline
\end{tabular}

653

654

655

656

657

658

659

660

661

662

663

664

665

666

667

668

669

670 
672

673

Table 8

\begin{tabular}{|c|c|c|c|c|c|c|c|c|c|c|c|}
\hline \multirow{2}{*}{$\mathrm{R}^{2}$} & \multirow{2}{*}{ DW } & \multicolumn{2}{|c|}{ Anova results } & \multirow{2}{*}{$\begin{array}{l}\text { Model } \\
\text { coefficient }\end{array}$} & \multicolumn{2}{|c|}{$\begin{array}{l}\text { Unstandardized } \\
\text { Coefficients }\end{array}$} & \multirow{2}{*}{$\begin{array}{c}\text { Standardized } \\
\text { Coefficients } \\
\text { Beta }\end{array}$} & \multirow{2}{*}{ T-test } & \multirow{2}{*}{ Sig. } & \multicolumn{2}{|c|}{$\begin{array}{l}\text { Collinearity } \\
\text { Statistics }\end{array}$} \\
\hline & & & & & Mean & $\begin{array}{l}\text { Std. } \\
\text { Error }\end{array}$ & & & & $\begin{array}{c}\text { Toleran } \\
\text { ce }\end{array}$ & VIF \\
\hline \multirow{3}{*}{0.85} & \multirow{3}{*}{1.82} & $\mathrm{~F}$ & Sig. & Constant & 45.60 & 1.21 & & 36.01 & 0.00 & & \\
\hline & & 1063 & 000 & $\begin{array}{c}\text { Coefficient of } \\
\text { FC }\end{array}$ & -0.17 & 0.03 & -0.129 & -5.378 & 0.00 & 0.72 & 1.37 \\
\hline & & 1003 & 0.00 & $\begin{array}{l}\text { Coefficient of } \\
\quad \mathrm{N} 1(60)\end{array}$ & 1.45 & 0.04 & 0.870 & 36.22 & 0.00 & 0.72 & 1.37 \\
\hline
\end{tabular}

674

675

676

677

678

679

680

681

682

683

684

685

686

687

688

689

690

691

692

693

694

695 


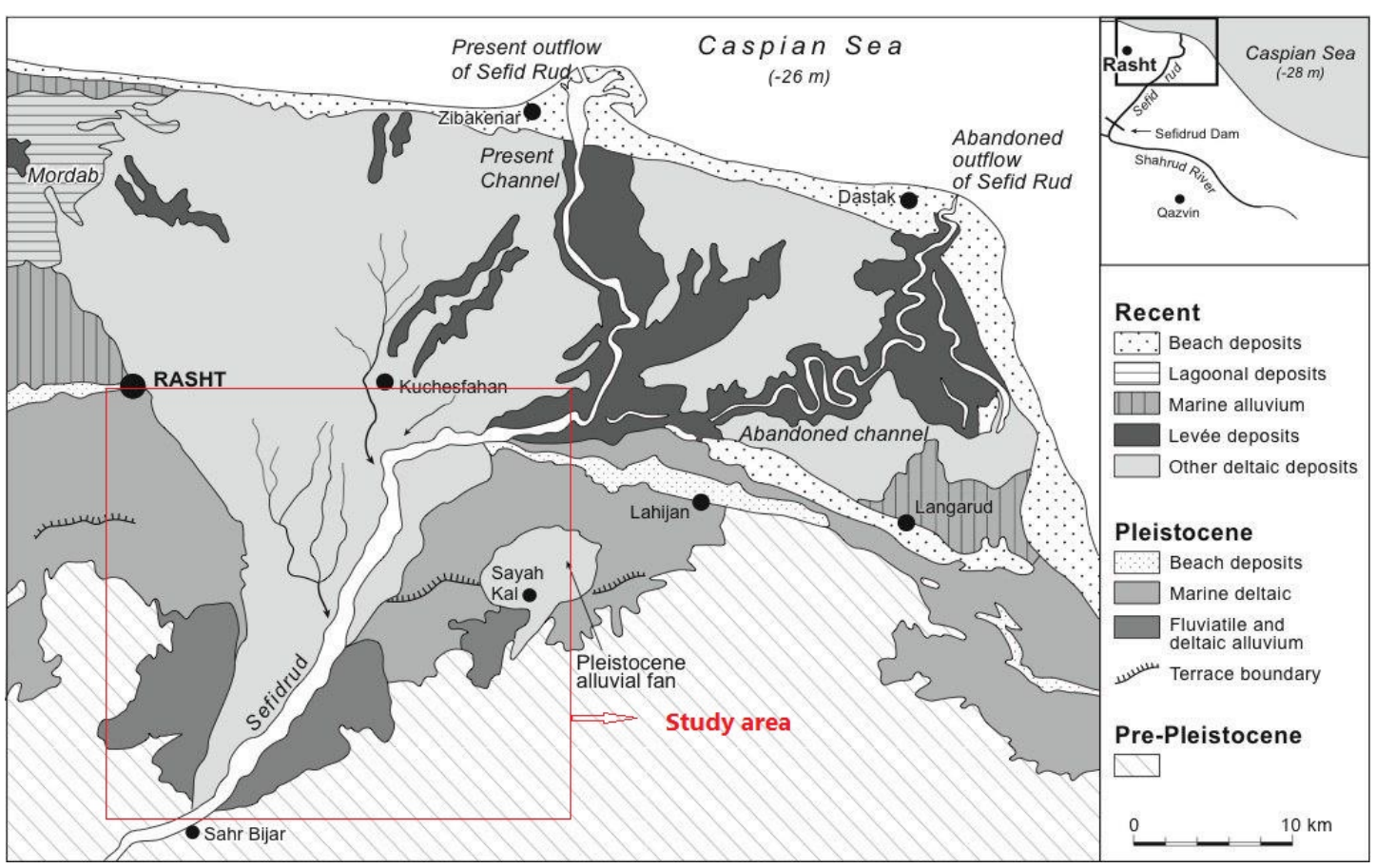

(a) 


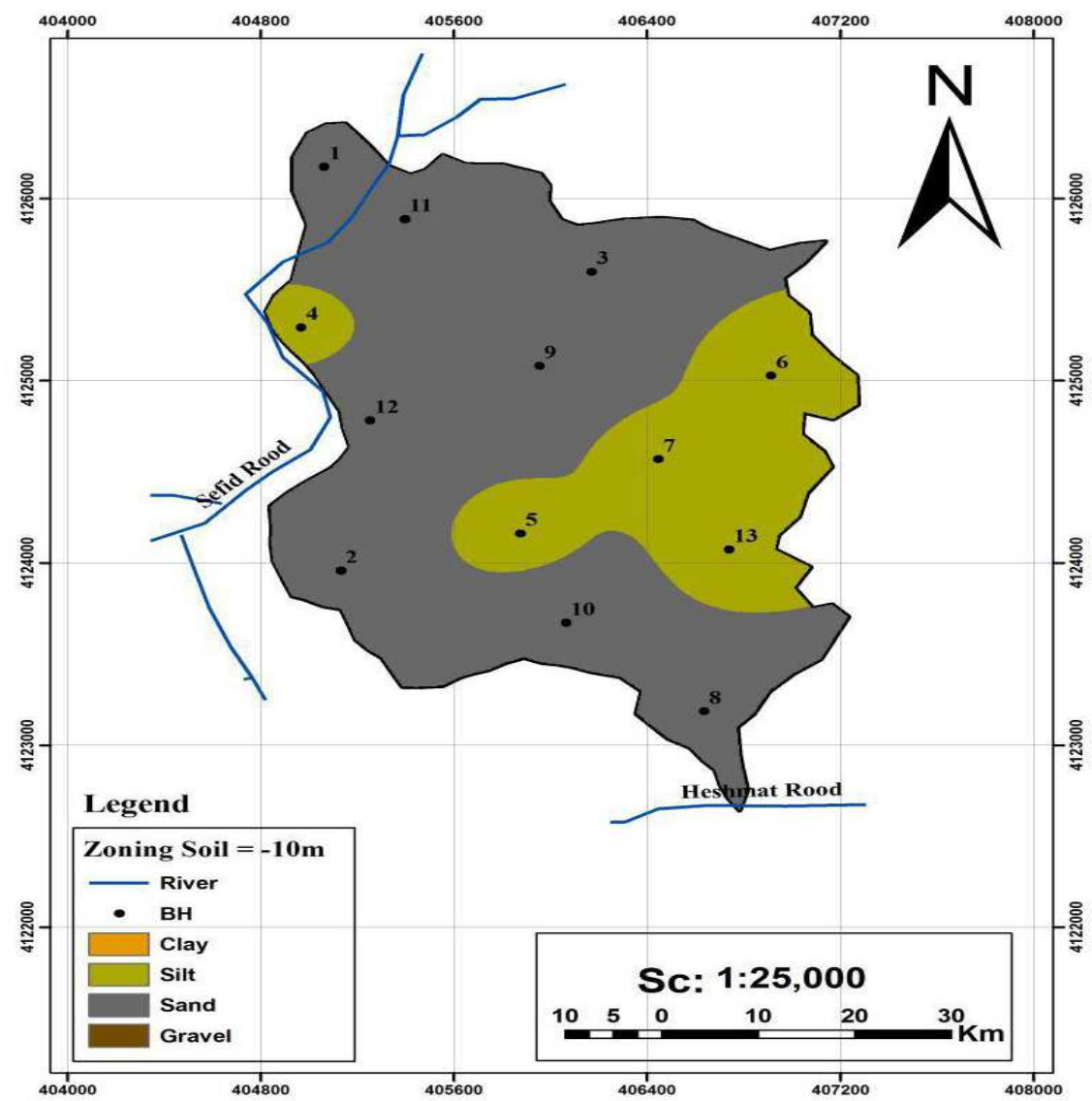

(b) 


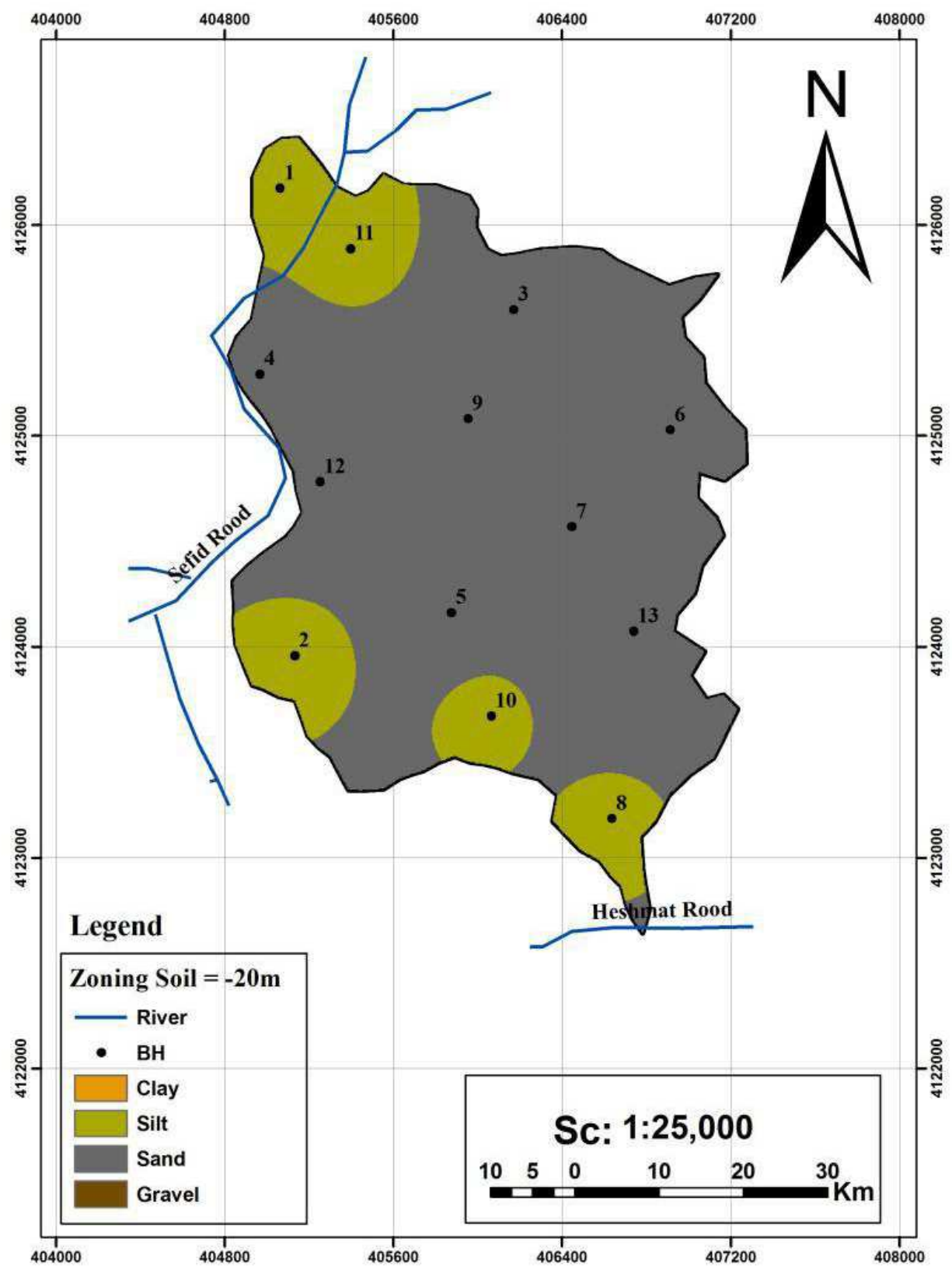

(c)

Figure 1. 
703

704

705

706

707

708

709

710

711

712

713

714

715

716

717

718

719

720

721

722

723

724

725

726

727 


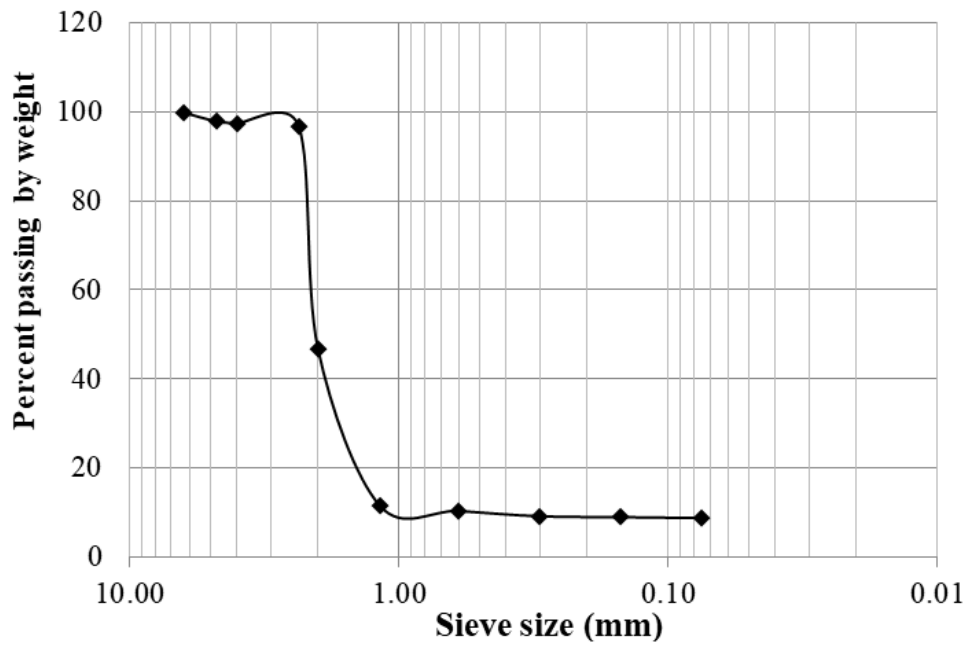

729

Figure 2.

730

731

732

733

734

735

736

737

738 

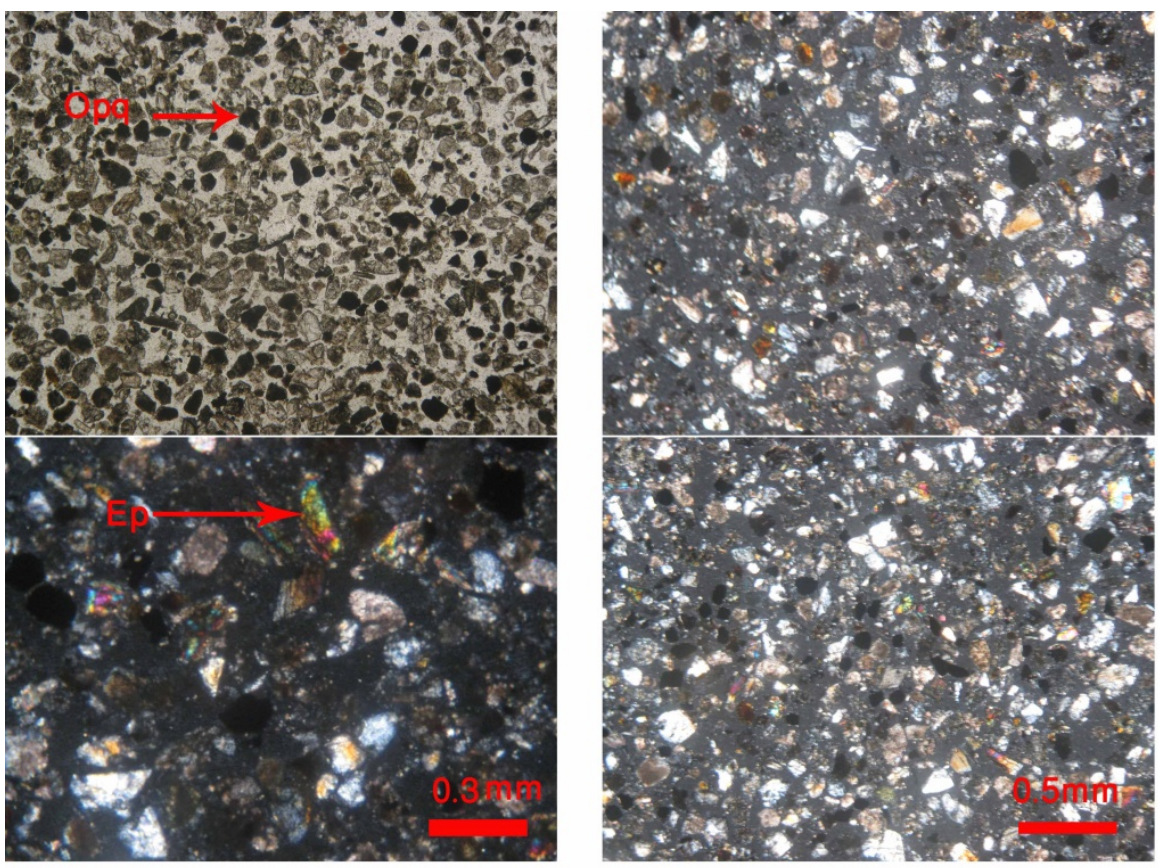

740

Figure 3.

741

742

743

744

745

746

747

748

749

750

751

752

753 


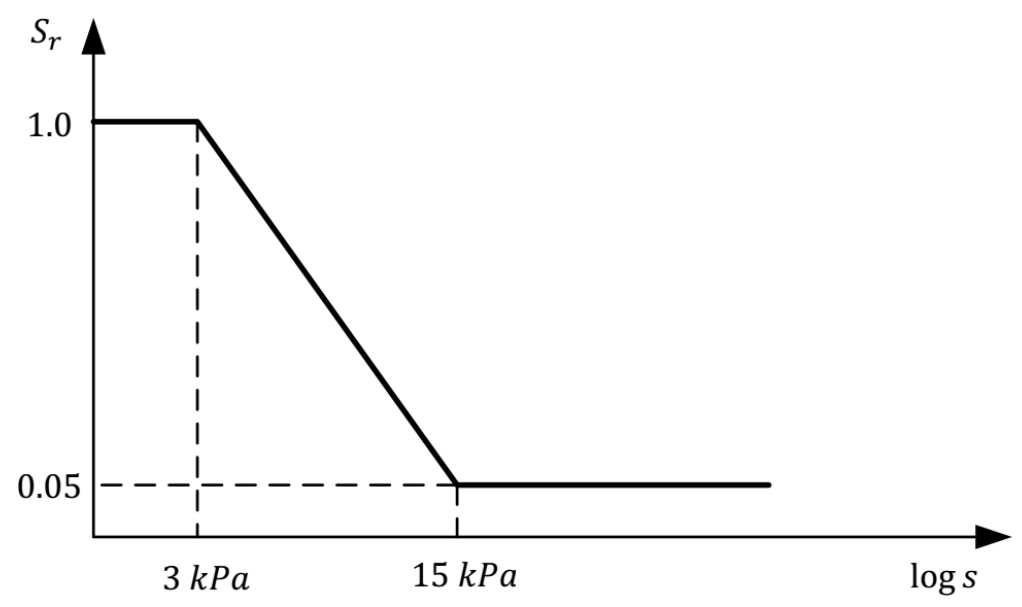

754

755

Figure 4.

756

757

758

759

760

761

762

763

764

765

766

767

768

769

770 

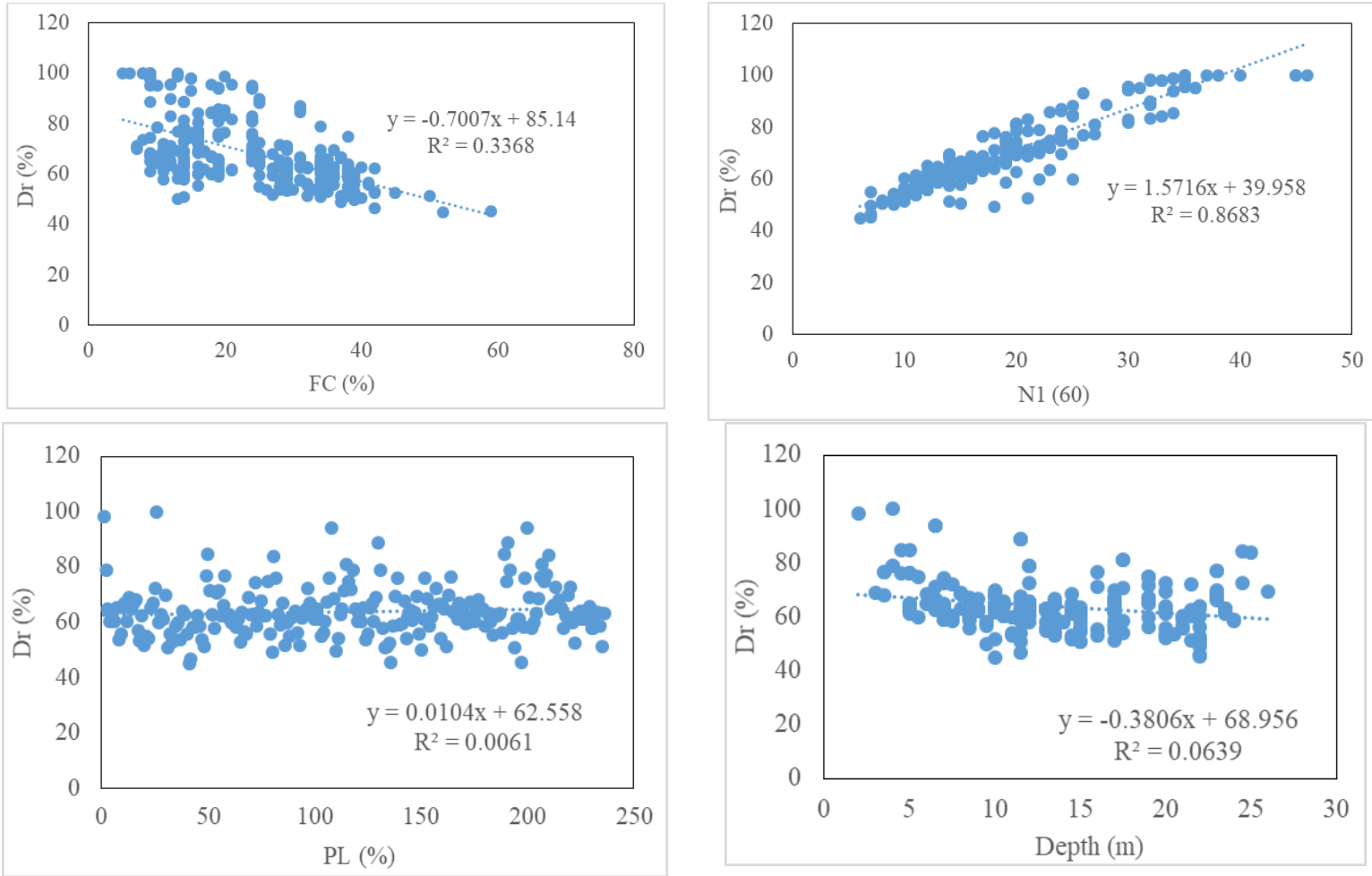

Figure 5.

772

773

774

775

776

777

778

779

780

781

782

783

784

785

786 
788

789

790

791

792

793

794

795

796

797

798

799

800

801

802

803

804

805

806

807

808

809

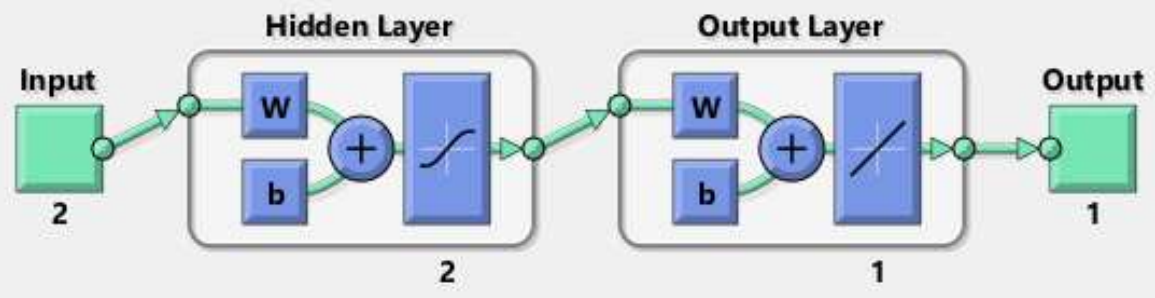

Figure 6. 


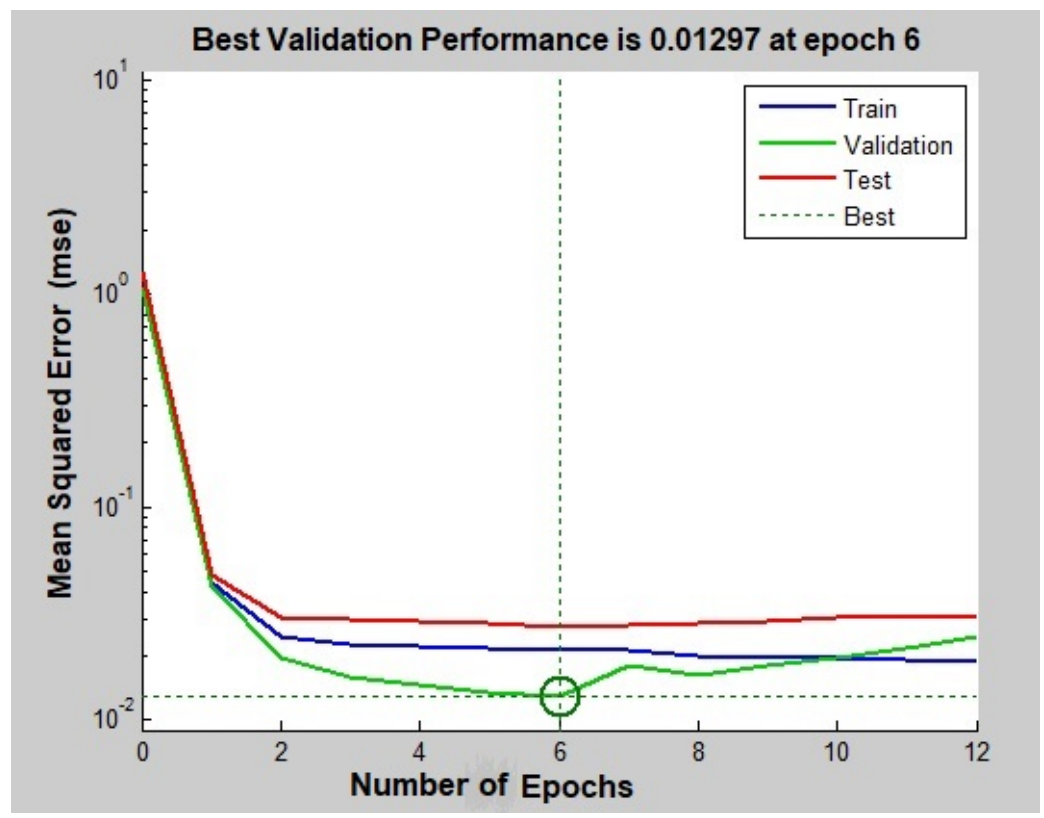

811

Figure 7.

812

813

814

815

816

817

818

819 

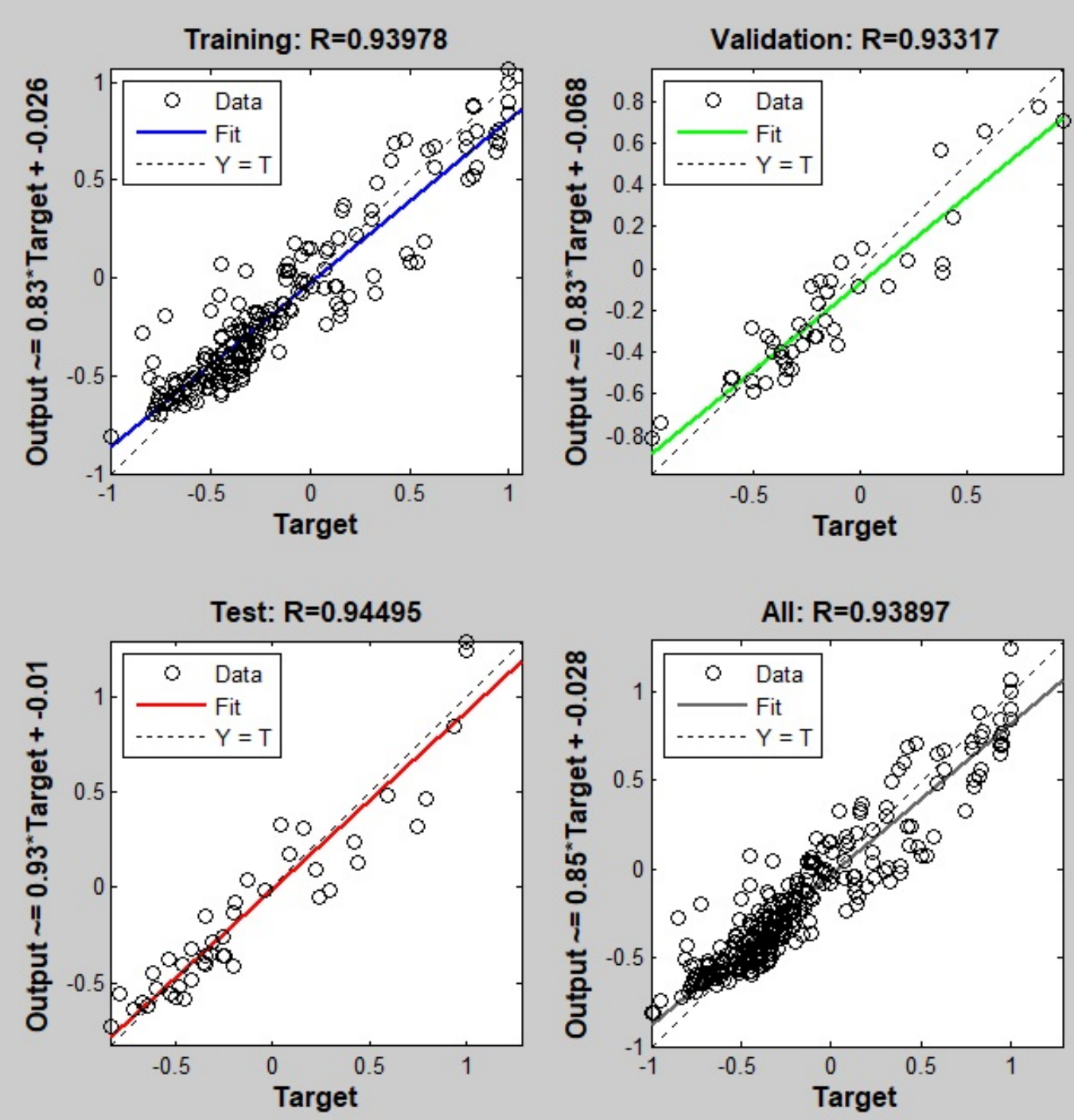
834

835

836

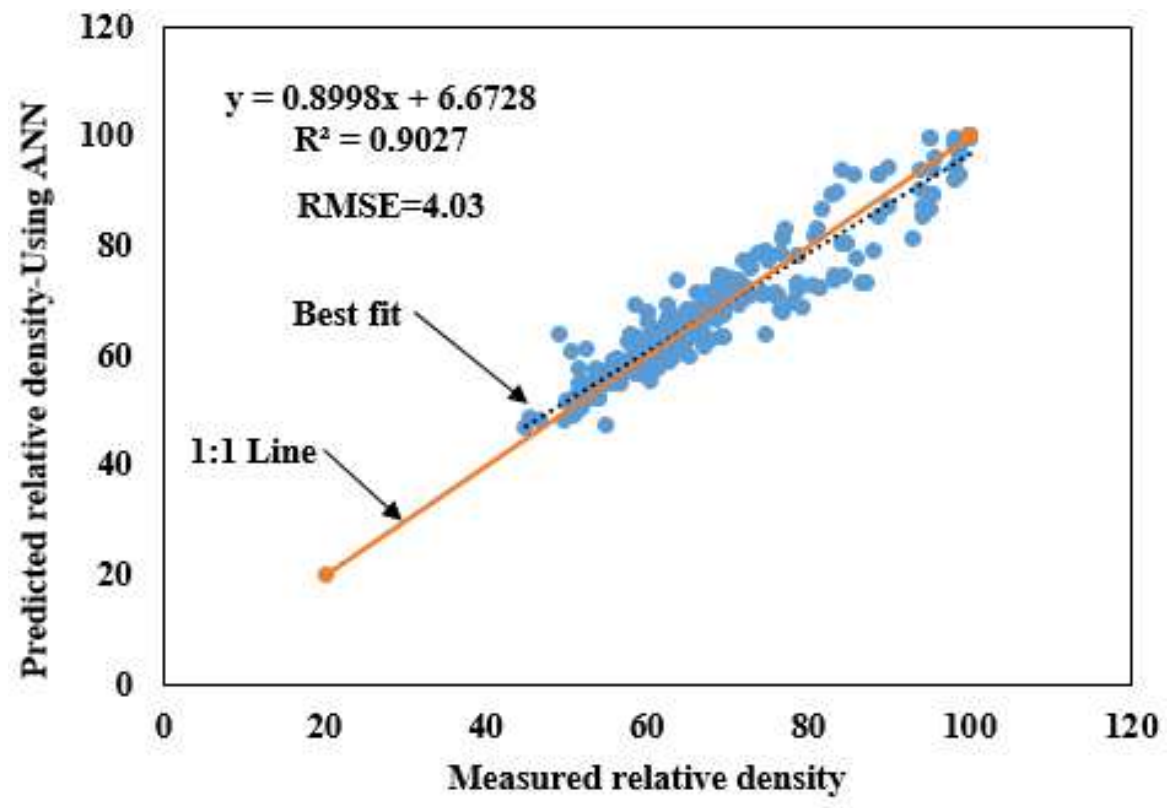

837

838

839

840

841

842

843

844

845

846

847

848

849

850

Figure 9. 


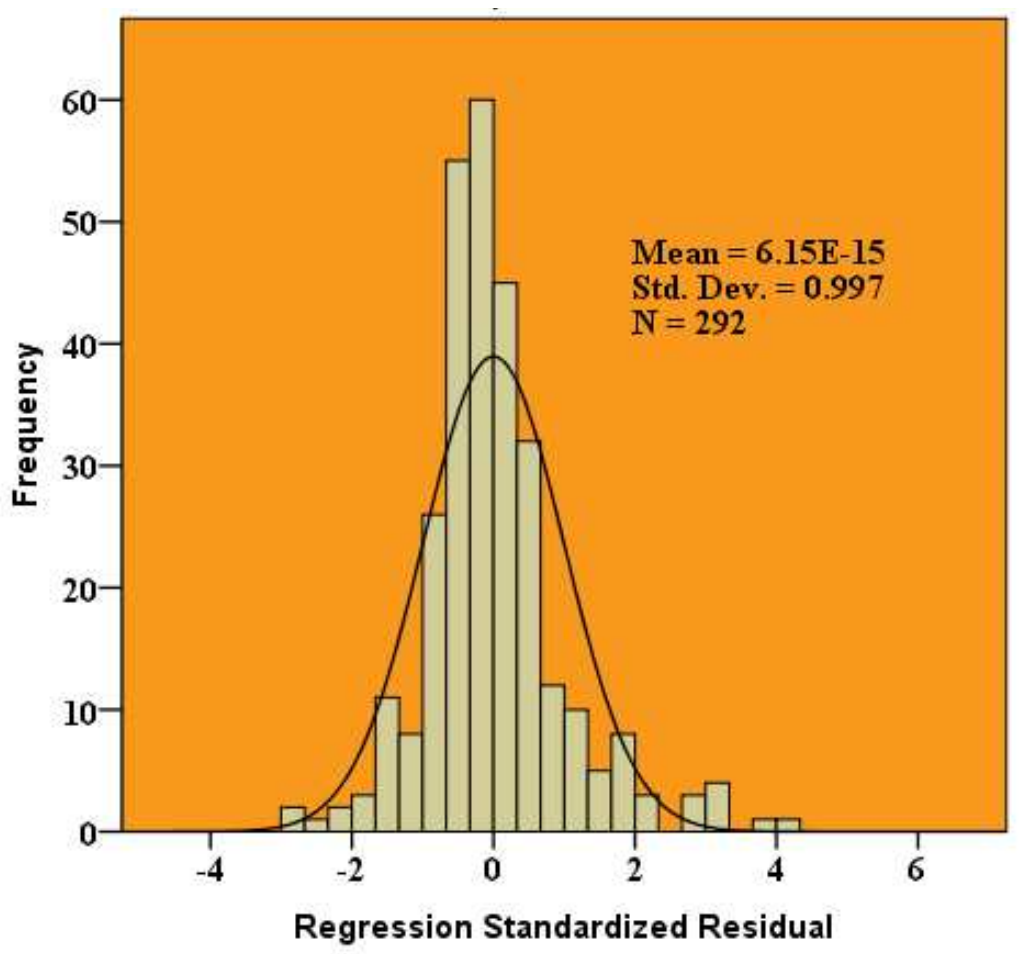

851

852

Figure 10.

853

854

855

856

857

858

859

860

861

862

863

864

865

866

867

868 
871

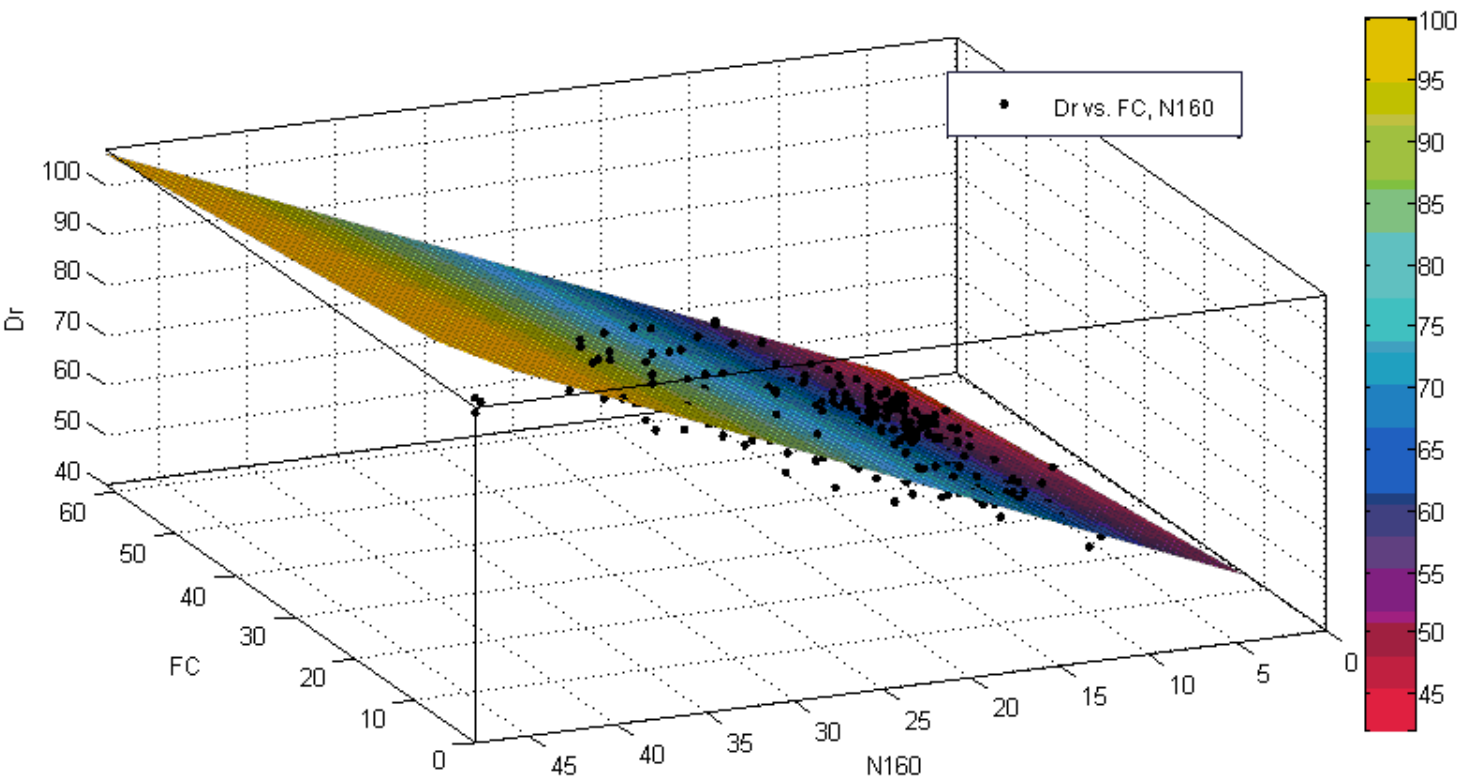

874

875

876

877

878

879

880

881

882

883

884

885

886

887 


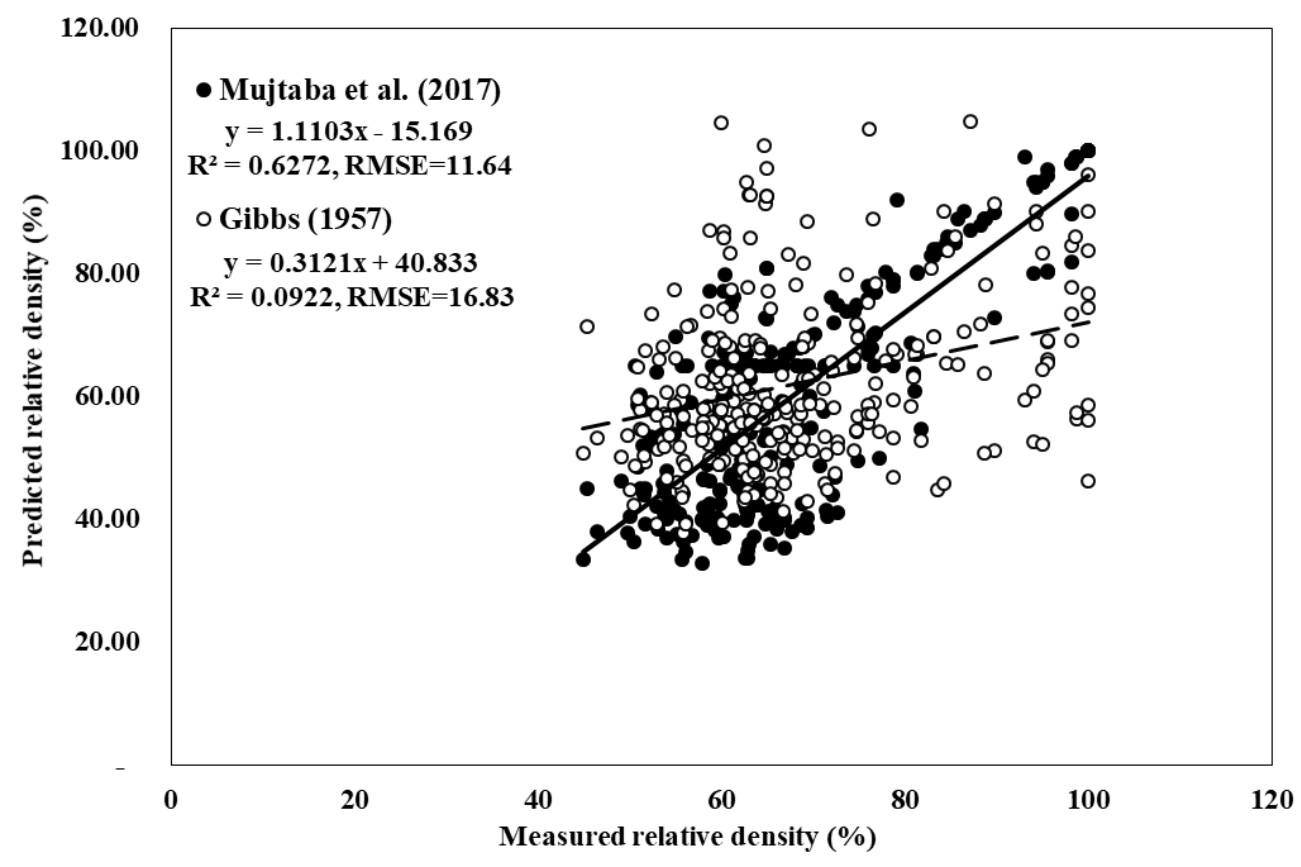

Figure 12.

890

891

892

893

894

895

896

897

898 


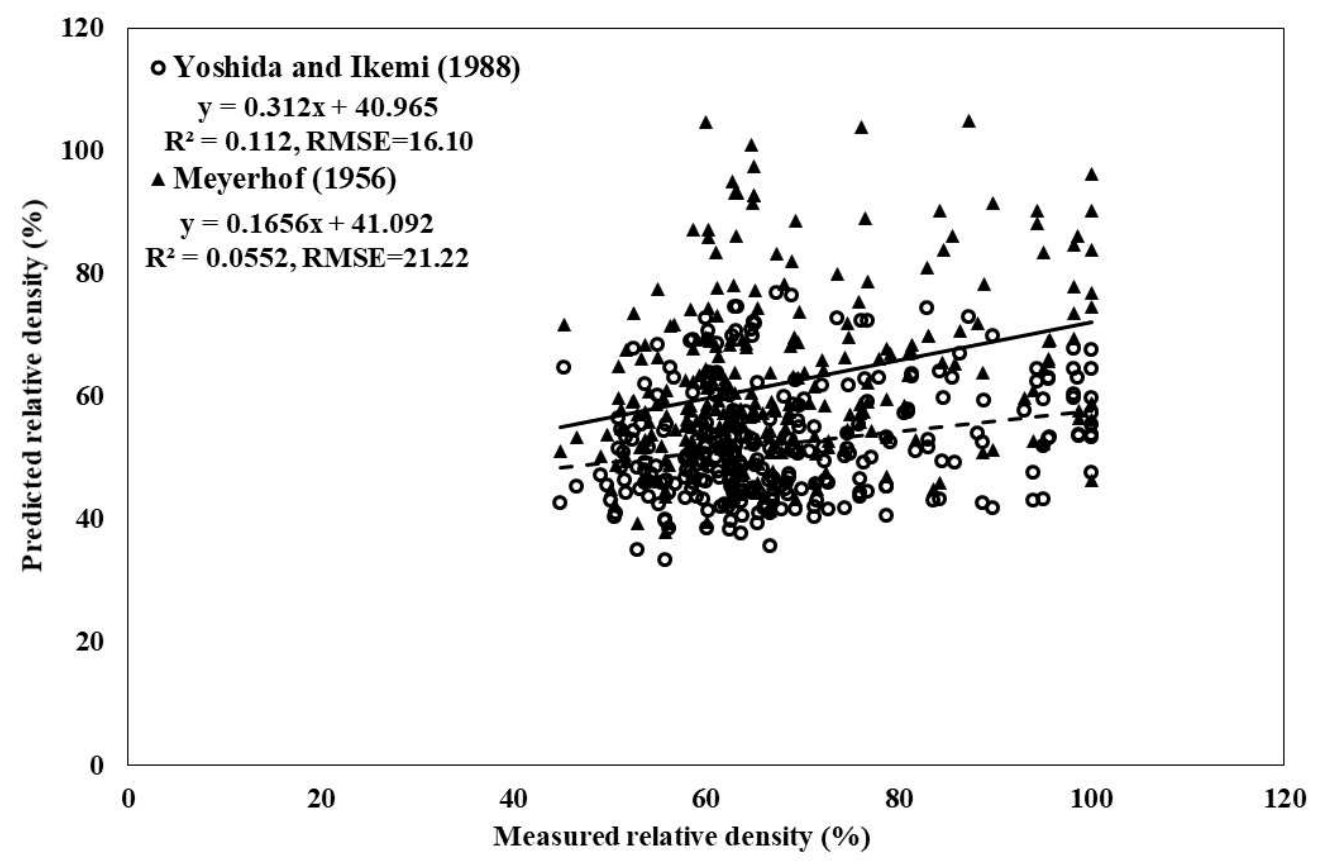

899

Figure 13.

900

901

902

903

904

905

906

907

908

909

910

911

912

913

914 


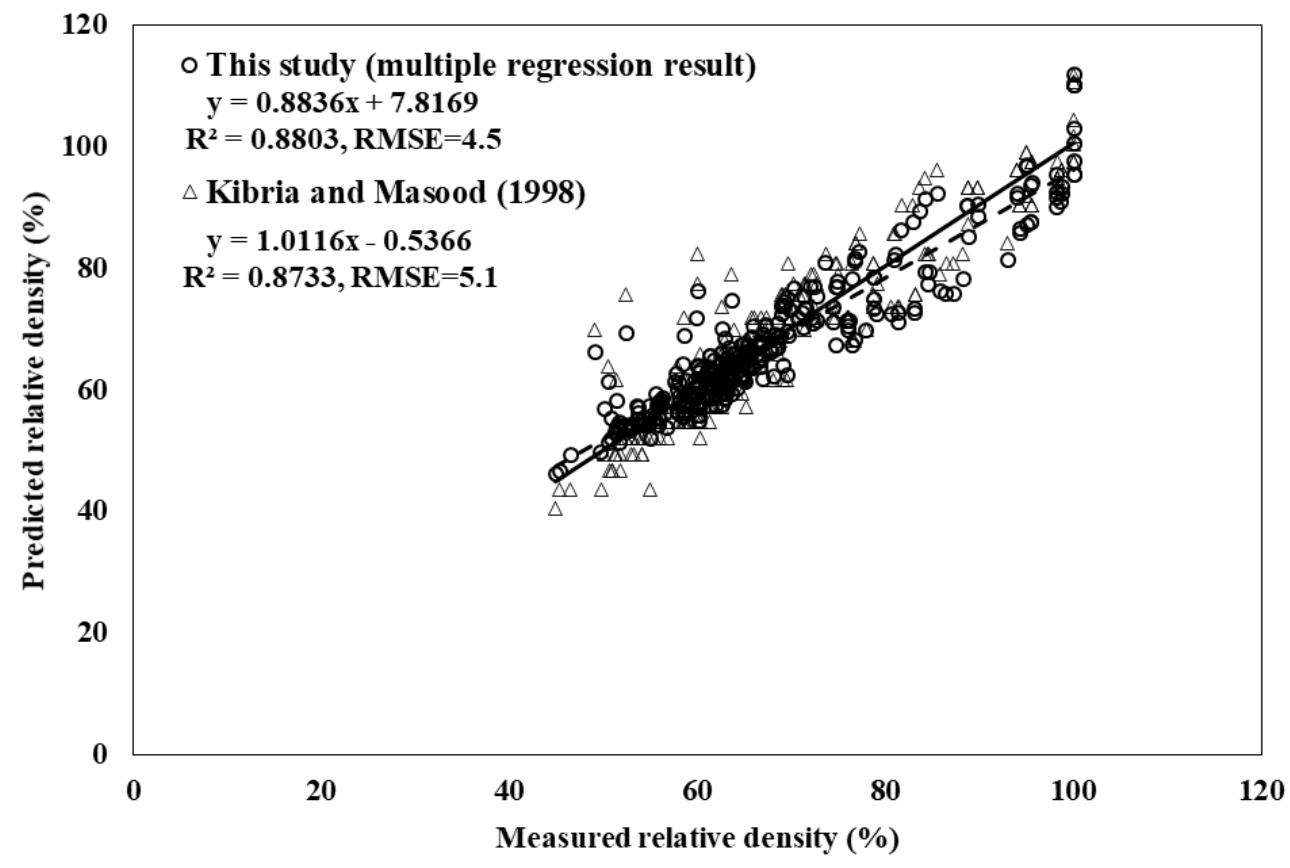

915

Figure 14.

917

918

919 